\title{
A Review of the Study of James's Philosophy over the Past Century in China and a Prospect of Future Research Work
}

\author{
Boya Geng1, Chengbing Wang2 \\ ${ }^{1}$ School of Philosophy, Beijing Normal University, Beijing, China \\ ${ }^{2}$ School of Philosophy and Sociology, Shanxi University, Taiyuan, China \\ Email: chinesegrace@163.com, wangchengbing@bnu.edu.cn
}

How to cite this paper: Geng, B. Y., \& Wang, C. B. (2020). A Review of the Study of James's Philosophy over the Past Century in China and a Prospect of Future Research Work. Open Journal of Social Sciences, 8, 227-244.

https://doi.org/10.4236/jss.2020.88020

Received: July 22, 2020

Accepted: August 21, 2020

Published: August 24, 2020

Copyright () 2020 by author(s) and Scientific Research Publishing Inc. This work is licensed under the Creative Commons Attribution International License (CC BY 4.0).

http://creativecommons.org/licenses/by/4.0/

\section{(c) (i) Open Access}

\begin{abstract}
William James was a major representative figure for American pragmatism. The study of James's philosophy and the translation and publication of James's works, both in China, are closely connected with the spread and study of pragmatic philosophy therein. The spread of Jamesian philosophy in China has gone through three stages: 1) From around the May Fourth Movement in 1919 to the 1940s, pragmatism started its journey in China; James's thought was introduced to the circles of scholars in China, and received criticism from Chinese scholars at the same time. 2) In the 1950s and 1960s, during the criticism against pragmatism among Chinese scholars, Jamesian philosophy was also fiercely attacked. 3) From the early 1980s to the present, scholars have tried to take the attitude of seeking truth from facts in commenting pragmatism, and attempted to re-examine pragmatism, including James's philosophy. In carrying forward the academic research on Jamesian philosophy, Chinese scholars should present its landmark achievements in the collation, edition, translation and study of classics concerning Jamesian philosophy, investigate important conceptions in James's pragmatism, study the clue of development and academic direction of thought therein, analyze and summarize James's position in pragmatic philosophy, and make clear the position and influence of James's philosophy both in the history of Western philosophy and in contemporary Western philosophy. Scholars should also do comprehensive multidisciplinary research on the philosophy of value, jurisprudential thought, philosophy of mind, political philosophy and religious philosophy in James's pragmatism, and meanwhile explore the dynamic relationship between Jamesian and Chinese philosophies from the perspective of comparative philosophy.
\end{abstract}




\section{Keywords}

William James ${ }^{1}$, Pragmatism, John Dewey over the Past Century in China

\section{From around the May Fourth Movement to the 1940s, James's Thought Was Introduced into China and Received Criticism from Chinese Scholars}

The period from around the May Fourth Movement to the 1940s witnessed the beginning of a journey of pragmatism in China; James's thought was hence introduced into Chinese academic circles and ideological and cultural circles, and meanwhile met with criticism from the scholars.

In the beginning of the 20th century, a remarkable phenomenon emerged in the eastward spread of Western learning. American pragmatism, as an academic trend of Western modern philosophy, rapidly developed into a summit of dissemination in China, which was one of the major signs of this phenomenon. The methodology of experimental sciences and the theory of truth about practice and utility, which are energetically promoted by pragmatism, as well as the democratic education advocated by pragmatist John Dewey, etc., reflected the need of the progressive Chinese intellectuals back then to oppose the impractical, obsolete academic style of "devoting the entire life to the study of texts" and promote new culture and new style of study, and meanwhile met people's requirements for sciences and democracy. An important sign of the climax of spread of pragmatism in China during this period was that pragmatic philosopher Dewey, by invitation, gave lectures to educational groups in 11 provinces and cities during his visit to China, with his lectures warmly welcomed and published on various journals and newspapers, respectively. In addition, Chinese scholars had written and published many essays to introduce, expound and comment pragmatism. According to incomplete statistics, merely around Dewey's stay in China, more than tens of relevant essays had been published.

\subsection{During His Journey in China, Dewey Systematically Introduced James's Philosophy}

From March 5, 1920 on, Dewey gave six lectures at the Hall of the Subject of Law of the Peking University, specially introducing the three philosophers of William James, Henri Bergson and Bertrand Arthur William Russell. In particular, his introduction to James and Jamesian philosophy was the most elaborate compared to the other two. Dewey's recommendation and analysis of Jamesian philosophy can largely be divided into the following aspects:

Firstly, James laid emphasis on individuality while he stressed the universality ${ }^{1}$ William James (1842-1910) was a major representative figure for American pragmatism, and one of the most important philosophers in the history of American philosophy. The research on James in China can be roughly divided into three stages. The paper explores the stages and points out the possible approaches to advance the future research on James in China. 
of mankind; he opposed absolutism, which asserts "only one truth". All important parts of Jamesian philosophy in James's late days were a development based on this. He gave his own philosophy two names: one is radical empiricism, and the other is pluralism. The former holds that the experience of mankind is universal and common, and cannot be generalized by a few abstract concepts; and the latter emphasizes that each person has his own individuality, and maintains that there are no absolute things. Dewey believed that these two points were extremely important to James's philosophy "because in his later period, his philosophy is based almost entirely on these two points" (Dewey, 2005).

Secondly, Jamesian philosophy mainly consists of three parts. The first part is about the origin of views, which led to the "radical empiricism" in James's terms. The experience in James is different from that in traditional empiricism, for the latter suggests that the experience of external things is stiffly impressed upon a passive mind, and asserts that knowledge is the duplication of facts, while "In James's Radical Empiricism, experience is active, adventurous, changing, forward-moving", and has a much wider scope than the previous so-called experience (Dewey, 2005). The second part is the effect of knowledge upon wishes, emotions and will, and the corresponding part is James's theory of "the will to believe". James believed that belief was just the will of actions, and meanwhile admitted that all philosophical disciplines include irrational will (Dewey, 2005). The third part is the question of the truth or falsity of knowledge, which is supposed to deal with the theory of truth. This is what James called "pragmatism". James did not agree on the correspondence theory of truth, nor the coherence theory of truth; instead, he was convinced that whether the imageries, views and theories are of truth or not consisted in the effects of their meanings. The theory that works is true, or otherwise it is false. As it were, James proposed "gradual growth and expansion of truth by means of experimentation and verification" (Dewey, 2005).

Thirdly, James opposed both absolute "dogmatism" and absolute "skepticism". He admitted that no truth can be found without doubt, but he also believed that absolute doubt means the lack of constructiveness. Jamesian philosophy has value not only because it breaks with previous absolute dogmatism and absolute skepticism, but especially because it advocates individuality, and firmly opposes the proposition of a "block universe". James criticized absolute philosophy as had jammed all things and principles all over the world onto a single track. Accordingly, James called "for human life to be a continual process of re-experimenting and re-creating” (Dewey, 2005).

And lastly, Dewey compared the philosophies of James, Bergson and Russell, pointing out that these three modern philosophers "represent the spirit of our time". He asserted that the difference between these three philosophers was quite superficial, and they were identical in essence, for they all advocated "creation, growth, change and transformation" (Dewey, 2005). To conclude, each of these three had made his own contribution. "James develops the concept of a dependable future which is active and flexible, and which can be freely created by those 
who live in it; his radical liberalism is a philosophy which invites each man to create his own future world. This is James's contribution" (Dewey, 2005). Bergson's emphasis on intuition adds an element of freshness to this creation of one's own future, especially when he insists that it is not a matter of rationalizing or calculating, but comes as a result of our innate impulse to forward striving. This is Bergson's contribution. Russell held that the broad and universal knowledge which is not subject to the limitations of the thinking of individuals can make up the deficiency of intuition and give direction to one's forward striving. This is Russell's contribution.

Dewey suggested that James shared a common point with Bergson because both of them had taken psychology as their starting point, and both had utilized the concepts of psychology in constructing their philosophies. They differed, however, in two important respects: first, in contrast to James's emphasis on experimentation, Bergson assigned a major role to introspection, and second, while James denigrated systematization in philosophy, and disclaimed any interest throughout in constructing a systematic philosophy, Bergson blended problems from all aspects into one philosophic system, setting up a systematic philosophy (Dewey, 2005).

\subsection{During This Period, Hu Shi Began to Spread Pragmatic Philosophy, Pedagogy and Ethics at All Aspects}

Around the May Fourth Movement, through translation, lectures and essays, $\mathrm{Hu}$ Shi introduced through translations, lectures and essays the pragmatic philosophy of the three representatives of pragmatism, namely Peirce, James and Dewey, becoming the first scholar systematically spreading pragmatism at all aspects in China. Hu's work had also exerted great influence on the academic methodology in China back then; as a participant in the intense debate about "problems and isms", Hu Shi, with his pragmatic propositions, developed a complicated and important relationship with Chinese political life at that time. Educator Tao Xingzhi energetically disseminated the pragmatic view of education, putting forward that education is the continuance of the transformation of experience, and that experimental education is an approach to new education and national prosperity; and also, he transformed and applied the educational method of pragmatism. Jiang Menglin likewise made great efforts in researching and disseminating pragmatic ethics and moral philosophy. These scholars had introduced James's philosophy more or less.

Firstly, Hu Shi discussed the status of James's psychology in the context of the history of Western philosophy. According to Hu Shi, James had exerted tremendous influence over both functional psychology and behavioral psychology, and James's psychology was a great revolution in the history of philosophy $(\mathrm{Hu}$, 2003). Hu Shi discussed James's thought about psychology by putting it into the history of Western philosophy, holding that James's psychology had actually absorbed something deserving to be affirmed in the rationalism and empiricism in the history of Western philosophy, and meanwhile tried to avoid and over- 
come the shortcomings of those two. In this sense, "James's greatest contribution to the history of philosophy is his 'new psychology"' (Hu, 2003).

Secondly, $\mathrm{Hu}$ Shi introduced the pragmatic theory of truth represented by James, analyzing the difference between James's theory of truth and previous philosophers' correspondence theories of truth first. Hu put forward that truth was an important issue in the history of Western philosophy, and that for a philosopher, the question consisted in what was meant by "correspondence with reality". Hu Shi held that both James and other pragmatic philosophers had attacked this theory of truth, and "thought this theory a static, inert theory of truth" (Hu, 2003). For, according to this kind of theory of truth, it seems that it is all right to directly copy the reality, and the function of thinking would be consummated so long as the duplication of the reality is gained. But in fact, correspondence is a kind of dynamic function of truth, "correspondence is the duplication of realities, but the response to realities, the acclimation to realities" (Hu, 2003).

Thirdly, Hu Shi specially introduced James's view that truth was an instrument, a go-between, a smoother-over of transitions, and then discoursed on the theory of truth about utility. For James, the truth can be recognized as a truth just because it has the value of a smoother-over of transitions or a go-between; a truth that has never acted as a smoother-over of transitions or a go-between has never been useful, so the corroboration of the truth consists in its satisfactory role as a smoother-over of transitions. "All theorems in sciences, all truths, either new or old, are go-betweens, either in-service go-betweens or retired ones, and the truth purely from the perspective of objects, which have never served as go-betweens or cannot serve as a smoother-over of transitions, have never existed" (Hu, 2003). Hu believed that James's theory of truth can also be called the "genetic theory of truth", for this theory of truth pays much attention to how the truth is generated, how it is gained, and how it becomes a recognized truth.

\subsection{Fan Shoukang Made a Meticulous Analysis of Pragmatic Empiricism in an Essay in 1933}

Fan clarified two points: first, pragmatism was a new movement in the circle of modern philosophy. In fact, this philosophy was a product of British empiricism, and took empirical philosophers, including Francis Bacon, John Locke, David Hume and John Stuart Mill, as its background. The difference is that James tried to push the view of experience in previous British empiricism a step forwards. The experience in terms of the traditional empiricism referred to the experience in common sense, while the experience in James is the pure experience in philosophy, that is, James had removed the dogmatic part of common sense out of the previously mentioned experience. This is James's radical empiricism.

Second, James started with radical empiricism, trying to address the most basic philosophical questions, that is, the relationships between mind and body, and between nature and consciousness. For James, the so-called nature (or body) and consciousness (or mind) are not distinctively different, for both are com- 
posed of the third, i.e. the elements common to both. These common elements are called the stuff of pure experience, or "materia prima". Therefore, both consciousness (mind) and nature (body) are composed of "materia prima". Pragmatism admits the existence of consciousness (mind), but such consciousness (mind) refers to no more than "the collectivity of empirical contents in a particular form". The so-called "stuff of pure experience or the materia prima itself is neither mind nor thing, but at the same time can be viewed as a neutral existence that is both mind and body. These common elements are not only subordinated to the two organizations of consciousness and nature at different times, but also to these two even at the same time, just as the intersection of two lines simultaneously belongs to the two lines". As pragmatists observe nature from the standpoint of radical empiricism, nature is absolutely neither the arena of electrons or neutrons, which are different from our perception, as most scientists have maintained, nor the uncognizable "thing-in-itself" in Immanuel Kant, nor the illusion created by our consciousness as subjective idealism has maintained. Nature is a thing co-existing with our consciousness, a thing made of the same material as consciousness is. There is no unbreakable barrier between nature and consciousness, and there is no absolute distinction between mind and body, between subjectivity and objectivity, or between self and other.

\subsection{James's Philosophy Underwent Criticism to Various Extents from Chinese Scholars before the 1930-1940s}

Firstly, Zhu Qianzhi's criticism against James's pragmatic theory of truth. Zhu published an essay "Comment on Pragmatism" in a form of serials in the third and fourth issues of the first volume of the New China, a Beijing-based journal in 1919. In this essay, Zhu expounded the source of pragmatism and its methodology, theory of truth, and realism. So to speak, this essay was a representative work of all-round critiques against pragmatism at that time. The author pointed out first, "Recent learning has been focused on pragmatism, of course, and the three doctors, namely William James, F. C. S. Schiller and John Dewey, are all masters of this school ... I dare not worship scholars although I value learning, and I would not follow blindly although I think highly of learning. Respecting what I can refute, I would certainly try my best to refute it, or the other way round, where the truth is unclarified, I would feel reluctant. But so long it is tenable and reasonable, I would accept it willingly". This passage indicates the author's attitude of scientific analysis towards pragmatism.

Zhu argued that pragmatism took truth as an instrument, for according to James, all truths had served as a go-between or a smoother-over of transitions for us. As for this, Zhu expressed his disproval by raising two questions: first, the changing contains the unchanging. We should also notice the principle that non-change is embedded into the change; second, change and non-change complement each other. There is no non-change independent of change, nor change independent of non-change. He emphasized the relationship between the objectivity of truth and the diverse forms displayed by truth (Zhu, 1919). 
Secondly, Fan Shoukang's critique about James's pragmatic empiricism and theory of truth. 1) The critique of James's view of experience. Fan held that the experience in pragmatism was not radical, and was thus exposed to the danger of falling into idealism. In light of pragmatic interpretations, according to Fan, the word "experience" had hidden the dispute between idealism and materialism. The term "experience" expressed an ambiguous meaning, so it was not radical. But one should also notice that "experience" was often confused with idealism, and that the "self" in pragmatism was conceptual and idealistic, of course. 2) The critique of James's pragmatic theory of truth. Fan argued that pragmatic theory of truth had three mistakes: first, the so-called "practical use" in pragmatism was extremely ambiguous, for nothing in the world could be viewed as absolutely in lack of practical use, science had its practical use, of course, but religion had its own practical use, too, all things had their practical uses at a certain aspect more or less. If practical use was taken as a standard for truth, all things and theories in the world could have been viewed as truths. Consequently, all reforms in the world would have been unnecessary. Moreover, the so-called "practical use" in pragmatism actually referred to the practical use to particular classes in modern society, and could never be interpreted as the practical use for mankind on a whole. Second, pragmatists held that all truths in the world were relative; if this had been true, there would never be absolute objective truth in the world. This would certainly deny that various truths in sciences were acquired by depending upon objective absolute truths, and that our consciousness was the correct reflection of objective absolute truth. This exposed the pragmatic theory of truth to the danger of skepticism. And third, pragmatists were wrong when they asserted that "it is true because it is useful", and the proposition should be reversed, and could only be that "it is true, so it can be useful". The former was the relationship between reason and induction, and the latter was that between cause and result. It could only be that "it is true, so it can be useful". The proposition that "whatever works is true" had reversed the relationship between cause and result into that between reason and induction.

Thirdly, Xie Youwei directed his critique of the pragmatic theory of truth from another perspective. He put forward that the pragmatic theory of truth was theoretically wrong, and had been criticized by Western philosophers. According to Xie, British thinker F. H. Bradley is the first to criticize pragmatism; Bradley pointed out that it was acceptable that there could not be truth unless an idea worked practically, but it was unacceptable to attribute all elements of truth to effectiveness. An idea could work not only because it existed and had been chosen by us, but also because we had chosen a proper idea. The idea that we had not properly chosen could not work. Xie pointed out that the pragmatic theory of truth had caused bad results in reality: firstly, it laid too much emphasis on the instrumentality of knowledge, and thus necessarily denied the value of all things themselves, and the value of man himself; secondly, it excessively stressed the utility of truth, holding whatever worked was true, and consequently encouraged hypocritical promotion; and thirdly, pragmatism determined every- 
thing at present and in the past with everything in future. Therefore, any belief did not appear as a truth because it had been true in the past, but was true because it would have a satisfactory result in the future. Pragmatism laid too much emphasis on future, and the consequence was necessarily that it ignored past, history and authority (Xie, 1947).

Fourthly, Fan Wenlan's criticism about the pragmatic view of history. In the essay On the Pragmatic View of Chinese History published in the first volume of the Treatise on Chinese History in 1944, Fan criticized the pragmatic view of history which pragmatism had promoted from the standpoints of subjective idealism and evolutionism.

\subsection{The Translation and Publication of Works by or Related to James}

Around the May Fourth Movement, the spread of pragmatism in China was mainly focused on introductory essays, and not many Chinese versions of James's own writings had been presented; the situation in the 1930-1940s was different, for apart from the publication of essays introducing and commenting pragmatism, Chinese scholars also translated and published some academic works by James himself.

James's writings that had translated into Chinese mainly included:

James: Pragmatism: A New Name for Some Old Ways of Thinking, translated by Meng Xiancheng, The Commercial Press, 1930.

James: Psychology: Briefer Course, translated by Wu Kuangfu, The Commercial Press, 1930.

James: Talks to Teachers on Psychology: And to Students on Some of Life's Ideals, translated by Tang Bohuang, The Commercial Press, 1936.

James: Chapter on Habit from The Principles of Psychology, translated by Tang Yue, The Commercial Press, 1944.

James: Chapter on the Stream of Thought from The Principles of Psychology, translated by Tang Yue, The Commercial Press, 1946.

James: Chapter on The Emotions from The Principles of Psychology, translated by Tang Yue, The Commercial Press, 1946.

Academic works related to James's philosophy mainly included:

Zhang Dongsun: Modern Philosophy, World Book, 1934.

Fan Qi: The Thoughts of Modern Philosophy, The Commercial Press, 1934.

Qu Junong: An Outline of Thoughts of Modern Philosophy, Zhonghua Book Company, 1934.

\section{Jamesian Philosophy Was Fiercely Attacked in the 1950s and 1960 in China}

In the 1950-1960s, Jamesian philosophy was embroiled in the criticism on pragmatism by Chinese scholars.

The harsh criticism against pragmatism from Chinese scholars after the founding of New China in 1949 began at the early1950s, and lasted until the late 
1970s. The movement to criticize pragmatism had its inevitability at that time.

During this censure on pragmatism, Dewey naturally became one of major targets due to his special relationship with $\mathrm{Hu}$ Shi and his direct influence upon traditional Chinese thought and culture. James, who is the founder of pragmatism and the most typical representative of pragmatic theory of truth and values, also suffered violent assault.

The major criticism against James and pragmatism can briefly be generalized into the following five aspects: first, pragmatism was a blindly adventurous philosophy; second, pragmatic philosophy was a decayed philosophy of subjective idealism; third, pragmatism was an obscurant philosophy against scientific and rational cognition; fourth, pragmatism was a philistine philosophy serving the big bourgeoisie; and fifth, pragmatism was of religion ${ }^{2}$.

\subsection{The Scholars Published a Series of Essays and Monographs against James's Pragmatic Philosophy}

Mainly including:

Chen Yuanhui: Criticism on Pragmatism, SDX Joint Publishing Company, 1954.

Li Da, Pragmatism-An Exclusive Philosophy of Imperialism, Hubei People's Publishing House, 1956.

Chen Yuanhui: Pragmatic Philosophy of Modern Bourgeoisie, Shanghai People's Publishing House, 1963.

Tang Yue: “A Criticism on James's Radical Empiricism", Philosophical Researches, No. 5, 1956.

Guo Yicen: "A Criticism of James's Proposition That 'Psychology as a Natural Science”, Journal of Beijing Normal University, No. 1, 1957.

Chen Xiuzhai: “A Criticism Against James's View About Individuals' Roles in History”, Journal of Wuhan University, No. 1, 1963.

Tang Bingshou: "A Criticism of James-Lange Theory of Emotion", Journal of Fujian Normal University, No.1, 1956.

\subsection{As By-Products of the Movements of Criticism against Pragmatism, Some of James's Writings Were Translated, Published or Re-Published}

The Principles of Psychology (translated by Tang Yue), The Commercial Press, 1963.

Essays in Radical Empiricism (translated by Pang Jingren), Shanghai People's Publishing House, 1965.

\section{The Research on James since 1980s in China}

From the 1980s up to the present, the study of pragmatic philosophy in Chinese scholars have been restored and gradually taken a normal course. After the end ${ }^{2}$ Regarding the criticism against pragmatic philosophy in the 1950s in China, please refer to Wang, 2002. 
of the Cultural Revolution, Chinese academic circles have tried to make a realistic, scientific evaluation of pragmatism, and reexamine pragmatic thoughts, including James's philosophy.

\subsection{Scholars Have Done Research Mainly at the Following Aspects}

Firstly, trying to carry out an all-round, scientific analysis of pragmatism. As for the attitude towards pragmatism, Chinese scholars have gradually abandoned the simplistic method of complete denial, proposed to re-estimate pragmatism, and maintained to make objective, all-round and precise research and critique of pragmatism, and avoid simplistic, rude behaviors. In terms of the overall evaluation of pragmatic philosophy, Chinese scholars, with a realistic academic attitude, have made objective commentaries on and analysis of many aspects of pragmatic philosophy by starting with the social, historical and scientific conditions for the emergence and development of pragmatic philosophy, and with the works of pragmatic philosophers themselves. With respect to the social and historical conditions for the emergence of pragmatism and the question of its theoretical source, Chinese scholars have realized that the emergence and development of pragmatic philosophy on a whole had their inevitability to a certain extent: It has generalized the life style and thinking mode of Americans and displayed multi-cultural characteristics. As to its academic status, pragmatic philosophy is a necessary link in the development of positivism in the modern West. In view of its emphasis on the effectiveness, simplicity and verifiability of thinking, just as its representative James had frankly admitted, it has been consistent with positivism. And also, Chinese scholars have carefully combed the internal thread and logic framework of classical pragmatic philosophy. Many scholars hold that classical pragmatic philosophy starts with the critique of metaphysics and is oriented on the pragmatic theory of truth. It is the most critical, interrelated part of pragmatic philosophy to oppose metaphysics, emphasize philosophy as a methodology, and think highly of the effect and usefulness of thought and theory (Liu, 1987; Li, 1997; etc.).

Secondly, having meticulously researched the important issues, conceptions and views of pragmatic philosophy, including James's philosophical conceptions.

Chinese scholars have fully realized that it is necessary to do in-depth and meticulous research on the critical conceptions in James's pragmatic philosophy. Chinese scholars have gradually focused on basic Jamesian conceptions including reality, experience, cognition, truth, meaning, morality, science, religion, society and politics, and begun to relatively objectively and clearly sort out their academic contents. This has played a positive role for us to learn about the basic conceptions and developmental thread of James's pragmatic philosophy.

Chinese scholars put forward that James maintained "reality" was what was related to and believed in by man. Correspondingly, James's theory of truth tried to highlight man's initiative, and criticized rationalism, especially dogmatism, which was far from life and one-sided in the philosophies of that time. Some 
scholars argue that many of our previous researches have ignored James's discourse on the question of humanistic basis for truth, and neglected the meaning of his criticism about the naturalist theory of truth and the mechanical materialist theory of truth, and even defined James's theory of truth as purely subjective idealism because he proposed that truth had a humanistic basis. They suggest that this simplistic understanding need to be reconsidered (Tu, 2006; Chen, 1998; Wang, 1992; Rao, 1998).

Thirdly, having re-examined the meaning of James's philosophy by tracking and researching neo-pragmatism. Since the 1980s, Chinese scholars have carefully discussed such questions as the revival of pragmatism, the characteristics of neo-pragmatism, the process and cause of the revival, and the relationship between old and new pragmatism. Chinese scholars believe that among the philosophers who announce themselves to be neo-pragmatists in public, the most influential are Richard Rorty and Hilary Putnam, both of whom had been influenced by James. They both opposed essentialism and denied the essentialist theory of truth, endeavoring to expound the pragmatic theory of truth. Putnam put forwards the "idealization theory of truth", holding that "truth is an idealization of rational acceptability", and that "theory of truth presupposes theory of rationality which in turn presupposes our theory of the good". In line with James's view, Rorty held that truth was a thing that had no essence, and could not be used to direct everything, so he asserted, "the way things are said is more important than the possession of truths". In the context of post-philosophical culture, Rorty pointed out that who were admirable were not those "who had won through to the Truth, but simply people who were good at being human". Some scholars argue that scientism focuses on the reflection on sciences, and abolishes the question of man, hence causing the split between science and man. Therefore, many philosophers of science have to resort to pragmatism when they encounter problems. For example, analytic philosopher Ludwig Wittgenstein's turn from his former period to his later days just displayed a remarkable pragmatic trend (Chen, 1998).

Fourthly, having tried to examine the pragmatic philosophy represented by James from such multiple aspects as culturology and market economy. Chinese scholars have put forward that the relationship between philosophy and culture is one of core issues that pragmatism has paid attention to. The pragmatism represented by James tries to re-understand the fundamental meaning of philosophy in this relationship at the aspect of metaphilosophy. This unique angle of understanding infiltrates pragmatism with a unique culturological meaning. In the eyes of James and some other pragmatists, no matter how philosophers believe they are seeking truth and describing reality, they have actually been dealing with conflicts between different social purposes, especially those between epochal development and tradition. Therefore, the history of philosophy is in essence a chapter of the history of civilization and culture, and the research on the history of philosophy must be combined with the study of anthropology, pri- 
mitive life, history of religion, literary history and social systems. In this way, philosophy gains its due humanistic nature as a compensation although it has lost its scientificity. Jamesian pragmatism tries to culturally restore philosophy and explain the emergence and development of philosophy through cultural conflicts. This idea has directly impacted on neo-pragmatism, and Rorty's theory of "post-philosophical culture" is just a development based on it.

With the rise of socialist market economy in China, scholars have begun to take its market economy as a general background in thinking about James and Dewey's pragmatism, and tried to provide help for the moral requirements in the construction of market economy in China. Some scholars have pointed out that the reason why market economy and the pragmatic theory of morality are put together to discuss is because there is a certain, even close, relationship between these two. In the development of Western market economy, there have been certain moral norm systems to keep pace with it all the time, which have been an important spiritual force to stabilize and adjust the order in Western society, and a requisite condition for the operation of Western market economy systems. All these norm systems must be based on certain theories of ethics and moralities, while the pragmatic theory of morality is a relatively typical one among them. James and Dewey's pragmatism has provided us with a sample of moral theory system with typical meanings in the West, for it has indicated the moral requirement of Western market economy in an intensive way. Through the research on pragmatic moral requirements, we can get some inspiration therein (Liu, 1995; Ding, 1994; Gao, 1994; Huang, 2017).

\subsection{Regarding Research Literature, Incomplete Statistics Shows That since the 1970s, Especially since the 1990s, Scholars in Mainland China Have Re-Published, Published through Revision and Newly Published More than 20 Chinese Versions of James's Classical Philosophical Works (including Chinese Versions Imported from Taiwan)}

1) James, The Principles of Psychology, translated by Tian Ping, Beijing: China City Press, 2006.

2) James, The Principles of Psychology, translated by Guo Bin, Beijing: Jiuzhou Press, 2007.

3) James, The Principles of Psychology, translated by Li Hongyan, Beijing: China Commercial Publishing House, 2009.

4) James, The Principles of Psychology, translated by Guo Bin, Beijing: Social Sciences in China Press, 2009.

5) James, The Principles of Psychology, bilingual in English and Chinese, translated by Tian Ping, Beijing: China City Press, 2010.

6) James, The Principles of Psychology, translated by Zhou Fang, Beijing: Beijing Institute of Technology Press, 2013.

7) James, The Varieties of Religious Experience: A Study in Human Nature, translated by Shang Xinjian, Beijing: Huaxia Publishing House, 2008. 
8) James, The Varieties of Religious Experience: A Study in Human Nature, translated by Tang Yue, Beijing: The Commercial Press, 2002.

9) James, The Varieties of Religious Experience: A Study in Human Nature, translated by Cai Yijia and Liu Hongxin, Guangxi: Guangxi Normal University Press, 2008.

10) James, Pragmatism: A New Name for Some Old Ways of Thinking, translated by Chen Yulun and Sun Ruihe, Beijing: The Commercial Press, 1979.

11) James, Pragmatism, translated by Yan Xiaodong, Chongqing: Chongqing Publishing House, 2006.

12) James, Pragmatism, translated by Chen Xiaozhen, Beijing: Beijing Publishing House, 2012.

13) James, Pragmatism: A New Name for Some Old Ways of Thinking, translated by Li Bulou, Beijing: The Commercial Press, 2012.

14) James, Behavior Change Theory, translated by Long Xiangtao, Nanhai: Nan Hai Publishing Co., 2014.

15) James, The Meaning of Truth: A Sequel to "Pragmatism", translated by Liu Hongxin, Beijing: Guangxi Normal University Press, 2007.

16) James, A Pluralistic Universe, translated by Wu Tang, Beijing: The Commercial Press, 1999.

17) James, Chapter on The Emotions from The Principles of Psychology, translated by Tang Yue, Taiwan: The Commercial Press, 1977.

18) James, in the Selected Works of Tang Yue, compiled by Zhou Yuemei and Chen Xiaohong, Beijing: Peking University Press, 2001.

19) James, Selected Works of William James, selected and compiled by Wan Junren and Chen Yajun, Shanghai: Shanghai Far East Publishers, 2004.

20) James, Selected Writings of William James, compiled by Wan Junren and Chen Yajun, and translated by Wan Junren and Chen Yajun, et al, Beijing: Social Sciences Academic Press, 2007.

21) James, Pragmatism: A New Name for Some Old Ways of Thinking, translated by Chen Yulun and Sun Ruihe, Beijing: China Youth Publishing House, 2013.

22) James, Pragmatism and Other Writings, Beijing: Communication University of China Press, 2016.

23) James, On a Certain Blindness in Human Beings, Beijing: China Translation \& Publishing Corporation, 2017.

24) James, Blind Points in Thinking, translated by the Ivy International Education League, Beijing: Modern Press, 2017.

25) James, The Principles of Psychology of a Professor of Harvard University, translated by Liu Xia, Beijing: World Publishing Corporation, 2017.

\section{Prospect of Future Research Work in China}

In accordance to our grasp and understanding of the quo status of related research, we think that the study of James's philosophy in China should be carried out around the following questions: 


\subsection{Carrying out Meticulous, Complete, Professional and Investigative Search, Collation, Edit, Translation and Study of James's Classical Works on Philosophy and Related Important Research Literature}

Philosophical literature is a major carrier for the thoughts of philosophers, and the research on the literature concerning James's philosophy is an important part of the investigation into James's philosophy itself. James had published such literature as The Principles of Psychology, the Pragmatism, The Varieties of Religious Experience and A Pluralistic Universe in his life, but did not systematically sort out or publish any collection of his works. After his death, especially since the mid- and late-1960s, American scholars began to pay attention to the collection, arrangement, collation, edit and research of James's literature. In particular, the most representative one is The Works of William James in 19 volumes, which took the Harvard University Press 13 years and is the most authoritative, most complete up to the present. The collection not only includes the literature that James had published when he was alive, but has also collected and sorted out the essays, works, lecture notes, ordinary notes, book reviews and interviews that James did not publish in life. The editors meticulously investigated each volume, and made clear introductions to the publication backgrounds and editing work of major texts, and linguistic experts added annotations and made revisions in the modern editions of the literature from the perspective of linguistics. In a certain sense, The Works of William James is a professional edition featuring academic criticism and textual research, and has high literature and academic value.

Since the 1920s and 1930s, Chinese scholars have translated and published some philosophical literature left by James, a few of which have even been published in several editions. After the 1980s, especially since the beginning of this century, the translation of literature on James's philosophy has made a progress to a certain extent, and a group of translated works have been published. However, these Chinese versions as literature still have considerable room for improvement: some versions are reprinted ones translated decades ago, and restricted by the level of academic research and the degree of understanding of James's philosophy at that time; the translation still has some room for further improvement in terms of the precise expression of thoughts, the proper use of terminology, and the comprehension of James's thought. Some versions are based on old English editions, and fail to reflect the achievements of compilation, collation and research in foreign scholars in the recent half century. Some versions have left too many parts out, and thus cannot objectively, completely or precisely reflect the full view of James's thought. Some versions are not translated by experts at philosophy, and are merely bilingual readings for English amateurs rather than philosophical professionals. Some English writings have more than one Chinese version, which quote and repeat each other blindingly, and do not show the research accomplishments of the translators; even worse, some translations are even low-level repetitions. Some versions are editions in- 
troduced from Taiwan, which have excessively remarkable difference in the translation of critical language and concepts, and could easily lead to misunderstanding ${ }^{3}$. Therefore, the immediate task for Chinese philosophers is to edit and publish a Chinese version of the complete collection of James's philosophical works, with The Works of William James as their basic literature.

The Chinese version of James's philosophical literature should include the following contents:

Pragmatism

The Meaning of Truth

A Pluralistic Universe

Principles of Psychology, Volume I

Principles of Psychology, Volume II

Principles of Psychology, Volume III

The Varieties of Religious Experience

The Will to Believe and Other Essays in Popular Philosophy

Some Problems of Philosophy

Essays in Radical Empiricism

Essays in Philosophy

Essays in Religion and Morality

Manuscript Essays and Notes

Manuscript Lectures

Essays, Comments, and Reviews

\subsection{Investigating the Development Clue and Academic Trend of Important Views and Thoughts in James's Pragmatic Philosophy, Analyzing and Summarizing James's Position in Pragmatism, Displaying the Significant Contributions That James's Philosophy Has Made in the Whole Pragmatism, and Highlighting James's Influence Which Has Been Necessary in the Development of Pragmatism but Often Neglected and Belittled by Scholars}

The research at this aspect will organically be linked with the study of James's personal thought and that of the history of development of ideas, and naturally will have to be combined with the investigation into the literature that records both James's conceptions and the development of his thoughts.

Chinese scholars should engage in in-depth research on key conceptions in James's philosophy. Such key conceptions in James's philosophy should include at least the following: metaphysical ideas, the theory of truth, the view of experience, the idea of the stream of consciousness and self-consciousness, the conception of religion, the conception of society and politics, pragmatism as a methodology, and so forth. In our opinion, it is necessary to research and dig out these key conceptions as "points" to enter the spiritual realm of James, start with these ideological points, in reference to the history of personal thought of James ${ }^{3}$ The achievements of the publication of James's literature in China will be published in another essay. 
himself and that of the development of pragmatism, to work out the "line" of the development of James's philosophy, and further display the contents and trend of Jamesian philosophy.

\subsection{Researching the Status and Influence of James's Philosophy Both in the History of Western Philosophy and Contemporary Western Philosophy}

Researching James's philosophy from the perspective of the history of philosophy is a hot point of research for foreign scholars, and also a weak link that urgently needs to be intensified in the research on pragmatism for Chinese academic circles. We propose to investigate the status and role of James's philosophy from the perspective of the history of Western philosophy and discuss the relationship between James's philosophy and traditional empirical philosophy on one hand, and research James's philosophy in the context of modern Western philosophy, discuss the relationships between James's philosophy and his contemporaries (Bergson, for example), and clarify the academic influence of James's philosophy upon contemporary philosophers such as Wittgenstein, Russel and Levinas (Wang, 2017).

\subsection{Carrying out Comprehensive Multidisciplinary Research on the Philosophy of Value, the Jurisprudential Theory, the Philosophy of Mind, Political Philosophy and Religious Philosophy in James's Pragmatism}

James's philosophy opposes empty talks and is concerned about realities, trying to infiltrate the general view of philosophy into many disciplines and topics. James's philosophy of value, his religious philosophy, his psychological theory, his philosophy of mind, his thought about society and politics, and the influence of James's philosophy upon pragmatic jurisprudence, all deserve our more in-depth research.

At this aspect, Chinese scholars are often restricted with disciplinary fields and academic horizons, and thus did little comprehensive research on James's pragmatism. We should have researchers in different fields to cooperate in their research on James's pragmatism, trying to gain breakthroughs in the holistic, multidisciplinary, multidimensional and comparative research on James's philosophy.

Figuratively speaking, if researching James's philosophy from the perspective of key concepts and conceptions is to dig out "points" in James's thoughts, and investigating James's philosophy from the aspects of philosophical and intellectual history is to find out the "lines" in James's philosophy, the multidisciplinary, comprehensive and holistic research on James's philosophy will be an attempt to represent the multidimensional philosophical thoughts of James.

\subsection{Exploring the Dynamic Relationship between Jamesian and Chinese Philosophies in the Horizons of Comparative Philosophy}

In the age of globalization, the dialogue between and comparative research on 
Chinese and Western philosophy are an important trend, and a challenge that contemporary Chinese philosophers cannot evade. The dialogue between pragmatic and Chinese philosophies has been held in pace with the introduction of pragmatism in China. Through nearly one century in the past, there have been turns, stagnation and even setbacks. Since the 1980s, a more profound dialogue between pragmatic and Chinese philosophies seems to have become inevitable thanks to the reform and opening up in China, to the widened and smoother communication channels, and to the attention that Western scholars pays to Chinese culture and philosophy due to the great growth of comprehensive strength of China. In this situation, Chinese scholars' level of research on pragmatism will determine the level and achievement of this dialogue to a certain extent.

The comparative study of Chinese and Western philosophy is an important but really very difficult work, which involves differences in terms of standpoints, culture and languages, etc. Trying to take the comparative study of Jamesian and Chinese philosophies as a case, this program may gain some achievements in solving problems in the comparative research on Chinese and Western philosophy, summarizing the methodology of comparative research of Chinese and Western philosophy, and exploring the new paradigm of comparative research.

As early as in the 1990s, some scholars have put forward the train of thought to do comparative research between Jamesian philosophy and both Yan Yuan and Huang Zongxi, and made some effective attempts (Chen, 1992; Lynn, 1990). In our opinion, apart from following a similar train of thought, researchers can also select some critical core conceptions to discuss, for example, James's concept of "radical empiricism", his view of the stream of consciousness and his ideas concerning oriental Buddhist philosophy ${ }^{4}$. At this aspect, we have both great room and confidence to make progress.

\section{Conflicts of Interest}

The authors declare no conflicts of interest regarding the publication of this paper.

\section{References}

Chen, L. (1992). A Comparison between James's Pragmatism and Yan Yuan's Thought on Practical Use. Journal of Nanjing Normal University, No. 4, 27-32.

Chen, Y. J. (1998). Reconstruction in Philosophy. Beijing: China Social Sciences Press.

Dewey, J. (2005). Dewey's Five Major Series of Lectures (pp. 230, 237, 230, 239-240, 240, 264, 264, 241, Interpreted by Hu Shi). Hefei: Anhui Education Publishing House.

Ding, L. Q. (1994). The Theoretical Misunderstanding of Pragmatism and the Conversion of Perspective. Philosophical Trends, No. 1, 27-30.

Gao, H. Z. (1994). The Fruit of Philosophy in the Age of Commodity Economy: A Review of Pragmatism. Journal of Shanghai Normal University, No. 3, 24-32.

${ }^{\frac{4}{4} \text { With regard to relevant ideas, see Shang, } 2002 .}$ 
Hu, S. (2003). Collected Works of Hu Shi (Vol. 1, pp. 287, 287, 292, 283, 294). Hefei: Anhui Education Publishing House.

Huang, Q. X. (2017). The Theory of the Stream of Thought and William James's Philosophy. Guilin: Guangxi Normal University Press.

Li, S. M. (1997). Summary of the "New Pragmatism" Seminar. Foreign Philosophy and the History of Philosophy, No. 3.

Liu, F. T. (1987). Reassessment of Pragmatism. In Modern Foreign Philosophy(Vol. 10). Beijing: People's Publishing House.

Liu, F. T. (1995). Market Economy and Moral Theory of Pragmatism. Hebei Academic Journal, No. 4, 26-32.

Lynn, S. (1990). A Common Base for Different Worlds: A Comparison between NeoConfucianism of the Ming and Qing Dynasties and American Pragmatism through Huang Zongxi and William James. Journal of Fudan University, No. 3, 26-31.

Rao, D. Q. (1998). A View of James's Pragmatic Theory of Truth. Journal of Xiangtan University, No. 4, 131-134.

Shang, X. J. (2002). The Secularized Religion of the United States and the Radical Empiricism of William James. Shanghai: Shanghai People's Publishing House.

Tu, J. L. (2006). From Classic Pragmatism to New Pragmatism. Beijing: People's Publishing House.

Wang, C. B. (1992). The Analysis of Pragmatism. Journal of Beijing Normal University, No. 2, 27-34.

Wang, C. B. (2002). Reflecting on the Criticism of Pragmatism in the 1950s in China. Educational Philosophy and Theory, 34, 155-159. https://doi.org/10.1111/j.1469-5812.2002.tb00294.x

Wang, C. B. (2017). Approaches to the Study of Pragmatism in Today's China. Educational Philosophy and Theory, 49, 1038-1044. https://doi.org/10.1080/00131857.2017.1347381

Xie, Y. W. (1947). A Review of Pragmatism. Thought and Times, No. 45.

Zhu, Q. Z. (1919). Comment on Pragmatism. New China, 1. 